\title{
LA-UR-14-27094
}

Approved for public release; distribution is unlimited.

Title:

Hot Press \& Furnace Line Execution Strategy

Author(s): Martinez, Danny Alex

Intended for: Report

Issued: 
Disclaimer:

Los Alamos National Laboratory, an affirmative action/equal opportunity employer,is operated by the Los Alamos National Security, LLC for the National NuclearSecurity Administration of the U.S. Department of Energy under contract DE-AC52-06NA25396. By approving this article, the publisher recognizes that the U.S. Government retains nonexclusive, royalty-free license to publish or reproduce the published form of this contribution, or to allow others to do so, for U.S. Government purposes. Los Alamos National Laboratory requests that the publisher identify this article as work performed under the auspices of the U.S. Departmentof Energy. Los Alamos National Laboratory strongly supports academic freedom and a researcher's right to publish; as an institution, however, the Laboratory does not endorse the viewpoint of a publication or guarantee its technical correctness. 


\section{Hot Press \& Furnace Line Execution Strategy}

Danny Martinez, NPI-8

Hot Press \#4 Project Manager

August 11, 2014 


\section{Outline}

- Scope

- Background

- Project Life Cycle Schedule

- Execution Strategy

- Work Scope by Fiscal Year

- Summary 


\section{Scope}

- To reliably support upcoming missions, it is necessary to install two new furnaces in GB 1235 and bring a new hot press with associated glovebox into operation. The new hot press is required to be operational by the end of FY17. 


\section{Background}

- Hot Presses 1 \& 2

- Were moved from the old LANL DP site to PF-4 in the late late 1970s - early 1980s

- Glovebox and Hot Press are late 1950s vintage

- Used for process development prior to formal manufacturing mission

- Cassini Mission (1993-1996), more than 750 pellets

- October 2001 Hot Press \#2 out of service due to induction feed thru failure. Occurred during coil replacement.

- Major corrective maintenance on Hot Press \#1 will be required in the near future that will add to the urgency in getting a new Hot Press

- Hot Press \#3 (new installation) started in early 90s

- Risk identified during Cassini

- Large funding cut upon completion of Cassini

- On hold since 1995 due to lack of funding

- Located in room during 2000 Type A Contamination Incident. 


\section{Hot Press System Description}

- Overview: To form a pellet, sintered granules are blended in the ratio of $60 \%$ low-fired and 40\% high-fired granules and loaded into a graphite die for hot pressing. The hot press system consists of a Materials Test Systems (MTS) hydraulic system, a vacuum system, a cooling system, and an induction heating system.

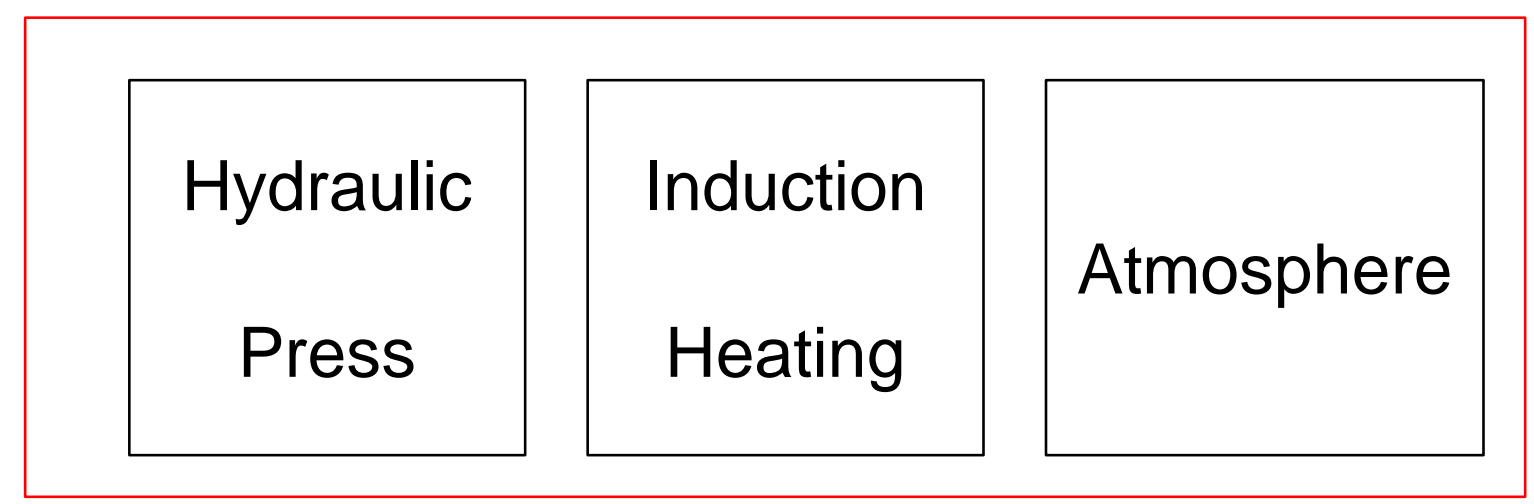

Glovebox

One of the Most Complicated Processes in PF-4 


\section{Hot Press System Description Cont.}
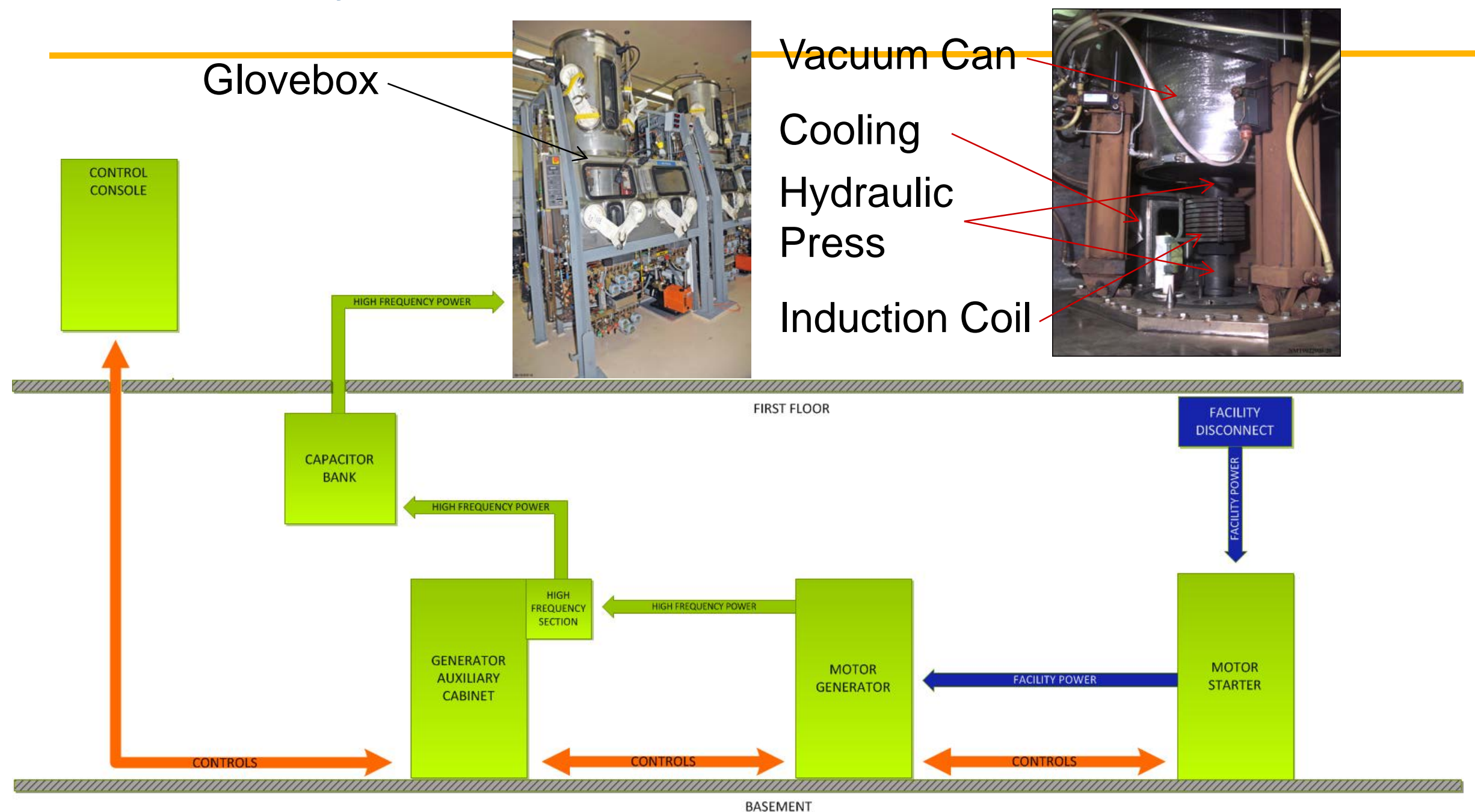


\section{Project Life Cycle}

\begin{tabular}{|ccc|}
\hline Fiscal Year & Major Focus & Cost per Year \\
\hline FY13 & Initiated requirements documents & $\$ .12 \mathrm{M}$ \\
\hline FY14 & $\begin{array}{c}\text { Technology Assessment \& } \\
\text { Removal of Existing Hot Press \#3 }\end{array}$ & $\$ 3 \mathrm{M}$ \\
\hline FY15 & Design \& Fabrication & $\$ 7 \mathrm{M}$ \\
\hline FY16 & Fabrication and Installation & $\$ 4 \mathrm{M}$ \\
\hline FY17 & Complete Installation \& Readiness & $\$ 2 \mathrm{M}$ \\
\hline
\end{tabular}

A preliminary contingency analysis has been performed on the FY15 scope. Current estimate is for a cost and schedule contingency of $\$ 1.2 \mathrm{M}$ and 2.4 month respectively 


\section{FY14 Scope}

\section{Hot Press}

- Develop D\&D design for existing hot press equipment

- Execute D\&D

- Hot press equipment technology assessment

- Develop procurement documentation

- Issue contract for hot press equipment

- Generate conceptual glovebox design

- Develop FY15 schedule

- Develop lifecycle schedule

\section{Furnace}

- Develop procurement specifications

- Order prototype furnace

- Perform facility upgrades in cold test facility

- Retrieve glovebox from storage

- Setup in cold test facility

- Evaluate glovebox shielding for compliance with RP requirements 


\section{GTAT: Commercial Hot Press System}

- Vendor: GT Advanced Technologies (formally Thermal Technology)

- Site visit revealed a highly capable company

- Experience with DOE Facility (INL)

- Procurement: Received RFQ on 7/30/14

- Cost \$919K (Design \& Fabrication)

- Delivery Schedule 39 weeks ARO

- Current Activities

- Technical Evaluation of RFQ

- Review of quote for compliance with specifications

_ Design kick-off target 8/18/2014 


\section{FY15 Scope}

\begin{tabular}{|l|l|}
\hline Hot Press & \\
\hline $\begin{array}{l}\text { - Design Change Form (DCF) closeout for D\&D } \\
\text { of existing hot press equipment }\end{array}$ & Furnace \\
\hline $\begin{array}{l}\text { - Design/Fabricate and cold test hot press } \\
\text { equipment }\end{array}$ & $\begin{array}{l}\text { - } \text { Update furnace glovebox design (seismic, } \\
\text { shielding) }\end{array}$ \\
\hline - Design hot press glovebox & - Modify furnace glovebox \\
\hline - Develop 60\% installation design & - Develop installation design \\
\hline - Cold test hot press equipment at LANL & - Procure production furnaces \\
\hline - Support equipment design \& fabrication & - Assemble control racks \\
\hline - Develop FY16 schedule & - Initiate software quality \\
\hline
\end{tabular}




\section{FY16 Scope}

\begin{tabular}{|l|l|}
\hline Hot Press & \\
\hline - Fabricate hot press glovebox & Furnace \\
\hline - Integrate hot press glovebox with equipment & - Integrate furnaces in glovebox \\
\hline - Install hot press glovebox & \\
\hline
\end{tabular}




\section{FY17 Scope}

\begin{tabular}{|l|l|}
\hline Hot Press & \\
\hline - Complete installation & Furnace \\
\hline - Close DCF & - Complete construction \\
\hline - Perform MSA/Readiness activities & - Close DCF \\
\hline
\end{tabular}




\section{Process Requirements (extra slide)}

- Hot Press

- Used to form fuel granules into densified pellets by compressing the fuel in a die while heated under vacuum

- Argon atmosphere

- $\quad \leq 0.1$ Torr (100 mTorr) vacuum

- $2800 \mathrm{lb}$ maximum pressing force

- $1600^{\circ} \mathrm{C}$ fuel temperature (heating ramp rate)

- Temperature soak of 30 minutes

- Simultaneously press and heat under vacuum 


\section{System (extra slide)}

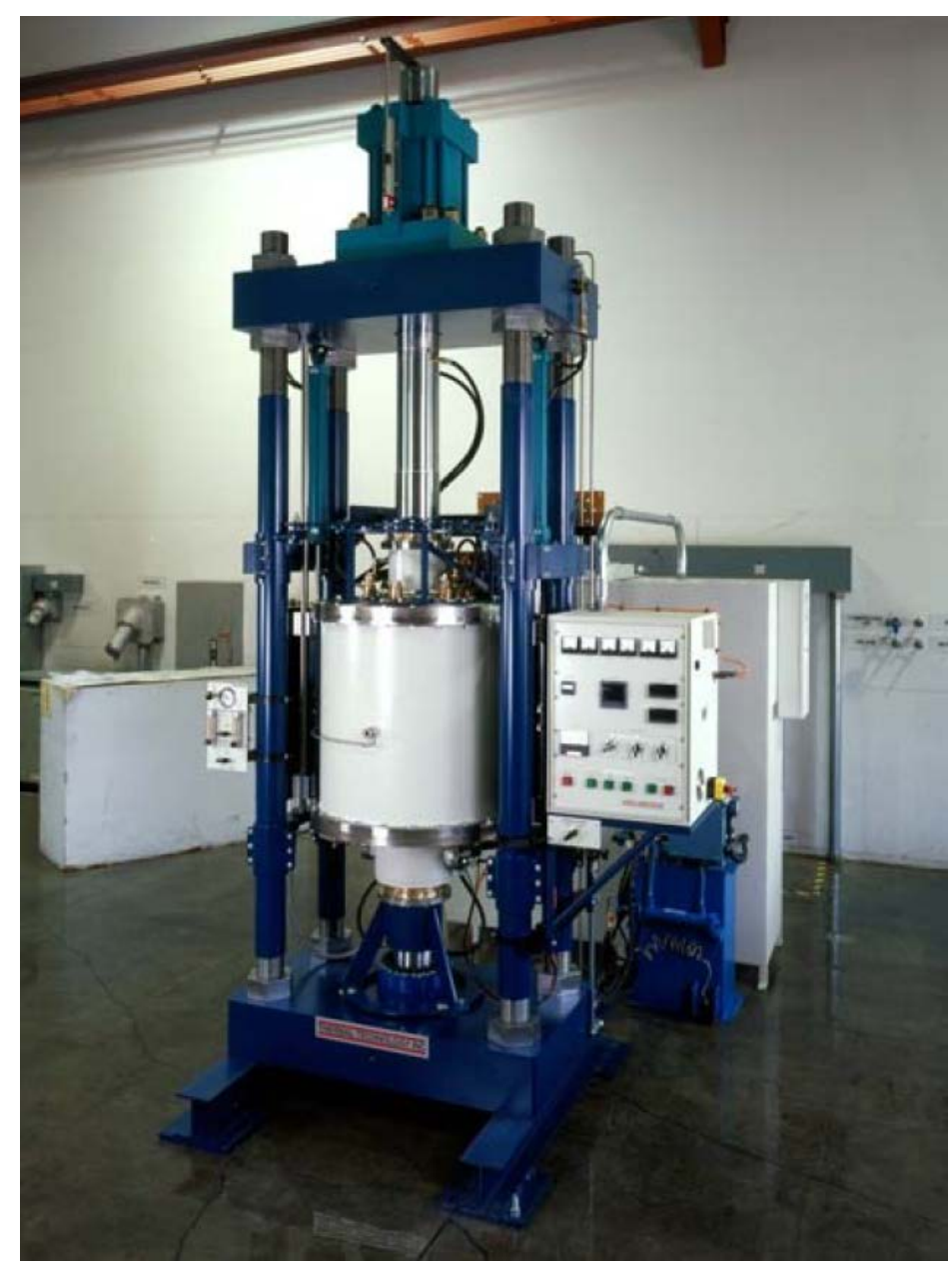

